\title{
How Does the Organizational Culture of Collaborative Networks Influence IT Governance Performance in a Large Organization?
}

\author{
Parisa Aasi \\ Stockholm University \\ parisa@dsv.su.se \\ Erik Perjons \\ Stockholm University \\ perjons@dsv.su.se
}

\author{
Lazar Rusu \\ Stockholm University \\ 1rusu@dsv.su.se \\ Martha Corrales Estrada \\ Tecnologico de Monterrey \\ mcorrales@itesm.mx
}

\author{
Dorothy Leidner \\ Baylor University and Lund University \\ Dorothy_Leidner@baylor.edu
}

\begin{abstract}
In today's complex organizations, IT governance is an important managerial challenge. IT governance deals with decisions and responsibilities concerning IT. There are many factors influencing IT governance. One factor that has remained relatively unexplored by academic research is that of organizational culture. This research explores the influence of the organizational culture of collaborative networks on IT governance performance. A case study was conducted in a large complex company with several networks. The findings indicated that the networks desire different organizational culture types based on their priorities for IT governance outcomes. A clan organizational culture is desired when aiming for effective use of IT for asset utilization and cost effective use of IT. An adhocracy culture is desired when prioritizing the effective use of IT for business growth. Finally a combination of market and hierarchy organizational culture is desired when seeking effective use of IT for business flexibility and cost cutting.
\end{abstract}

\section{Introduction}

It is becoming more and more evident that Information Technology (IT) enhances an enterprise's capacity for survival in today's highly competitive world $[1 ; 2 ; 3]$. Therefore, managing IT and using it as a strategic driver to the businesses is a high priority for organizations $[4 ; 5 ; 6]$. However, governing IT in such a way to enhance IT value remains a major challenge [7; 8; 9]. This challenge is detectable in a large number of IT governance implementation projects that fail every year and result in massive costs [10].

IT governance deals with IT decision rights and responsibilities required to achieve value from IT investments based on business objectives [11]. Both practitioners and researchers have emphasized the benefit of IT governance. For example, according to several researchers IT governance has a significant influence on the overall performance of an organization $[5 ; 12 ; 7]$. Moreover, the Sarbanes Oxley Act of the U.S. emphasizes the need for IT governance in organizations $[13 ; 14]$.

In recent years many large organizations have begun using complex organizational patterns such as global virtual networks in order to enhance the quality of collaboration and decisions $[15 ; 16 ; 17 ; 18]$. In virtual networks, organizational members use technology to interact and collaborate with each other regardless of the boundaries, such as geographical and organizational boundaries [19]. In organizations with global virtual networks, IT governance can be complex to implement with such questions as "who makes which IT decisions" difficult to answer [20;6].

There are many factors that should be considered when implementing IT governance in complicated organizations with global virtual networks; among which is that of organizational culture $[21 ; 22 ; 23]$. Organizational culture can be defined as "the set of shared values and norms that control organizational members' interactions" [21, p. 177]. Organizational culture can be used to support IT governance implementation or it can hinder effective governance [24].

Previous researchers call for more empirical research on IT governance and organizational culture $[25 ; 26 ; 27 ; 28 ; 29 ; 30]$. Specifically in the context of IT governance in global virtual networks, there is scarce research on the influence of organizational culture on IT governance performance.

This research aims to explore the influence of the organizational culture of networks on the IT governance performance. In particular, we address the research question: "How does organizational culture influence IT governance performance in global virtual networks in a large organization?" In order to respond to this question, a case study in a complex organization 
(Cemex) with global virtual networks and distinctive leaderships was conducted.

The remainder of this paper includes the research background, conceptual framework, methodology, case description, data analysis, and discussion, and finally the conclusions, limitations, and future research.

\section{Research background \\ 2.1. IT Governance}

IT governance as an integral part of enterprise governance [2] consists of the "leadership and organizational structures and processes that ensure that the organization's IT sustains and extends the organization's strategies and objectives" [31, p. 10]. In this paper, IT governance is defined as "specifying the frameworks for decision rights and accountabilities to encourage desirable behavior in the use of IT"' [11, p. 2].

2.1.1. IT governance performance. IT Governance performance assesses IT effectiveness through the following four objectives weighted by their importance to the enterprise:

1) Cost effective use of IT - which comprises how much IT is beneficial for business.

2: Effective use of IT for growth - which concerns how IT is effective in learning, being innovative, gaining competitive advantage and making improvements.

3: Effective use of IT for asset utilization - which focuses on how successful IT is in using knowledge based assets in organization.

4: Effective use of IT for business flexibility which investigates how IT is successful for the business in responding to the internal and external changes [11].

The above objectives are used in this research in identifying IT governance performance.

2.1.2. IT governance in global virtual networks. Global virtual networks include members that collaborate, communicate, and perform different tasks regardless of geographical or organizational boundaries using information technology [19]. This form of organization is relatively new and strongly dependent on IT, therefore IT governance is a crucial issue [20]. Organizations increasingly use virtual networks to respond to their dynamic environment on time. Moreover, the virtual networks allow organizations to work through their global and decentralized work processes [32]. Different virtual networks in an organization may have different types of leadership, goals, culture and priorities and use IT in different ways that can impact the IT governance performance of the organization [16]. Therefore it is important to identify the influence of organizational culture on IT governance performance in networks.

\subsection{Organizational culture}

Organizational culture can be described as " $a$ pattern of shared basic assumptions that was learned by a group as it solved its problems of external adaptation and internal integration, that has worked well enough to be considered valid and, therefore, to be taught to new members as the correct way to perceive, think, and feel in relation to those problems" [33, p. 17]. Organizational culture is counted among the factors having an important influence on IT governance [34].

\subsubsection{Four types of organizational culture.} Different models and dimensions have been introduced to identify organizational culture [35; $33 ; 36]$. In this research the dimensions introduced by Cameron and Quinn [35] are used to identify organizational culture. They developed an instrument called Organizational Culture Assessment Instrument (OCAI) and categorize organizational cultures into four types (clan, adhocracy, hierarchy and market) according to four core values through which the organization is recognized. These four organizational culture types are different through two main aspects: 1) Internal focus and integration versus External focus and differentiation; 2) Stability and control versus Flexibility and discretion.

\section{The Clan Culture}

In an organization with a clan environment, people share many things with each other. Loyalty is an important factor that leads to high commitment. Teamwork and participation have a high priority in a clan culture organization.

\section{The Adhocracy Culture}

In an adhocracy culture the emphasis is on being creative, entrepreneurial and dynamic. The organization is risk-taking and moves to be the pioneer on its own business. Their aim is growth and leading in the product or service they provide. Individuals have freedom for creativity as an important commitment.

\section{The Hierarchy Culture}

In a hierarchy organizational culture there is a highly formalized and structured work environment with procedures for everything. Leaders are not risk-taking or innovative and they are more efficiency minded instead. Such organizations consider themselves efficient when they meet the needed delivery, follow the formal rules on time, and have a low cost.

\section{The Market Culture}

A market culture organization is result- oriented. The concern is getting the job done on time and competition is crucial. The leaders are drivers 
and compete a lot. Organizations are considered successful if they have a notable share in the market and have high demand for their products or services [35].

OCAI is used in this research since it is a validated tool used by over 10,000 companies worldwide [37]. Moreover, consultants can use OCAI making constructive changes through new teams, leaders, and working methods [38].

\subsection{Research conceptual framework}

As shown in Figure 1, the research is directed through the conceptual framework to find out which type of organizational culture can be suitable for each of the IT governance outcomes in different networks. The organizational culture types in the networks are identified using the OCAI model [35] and the IT governance performance is distinguished using four IT governance outcomes introduced by Weill and Ross [11].

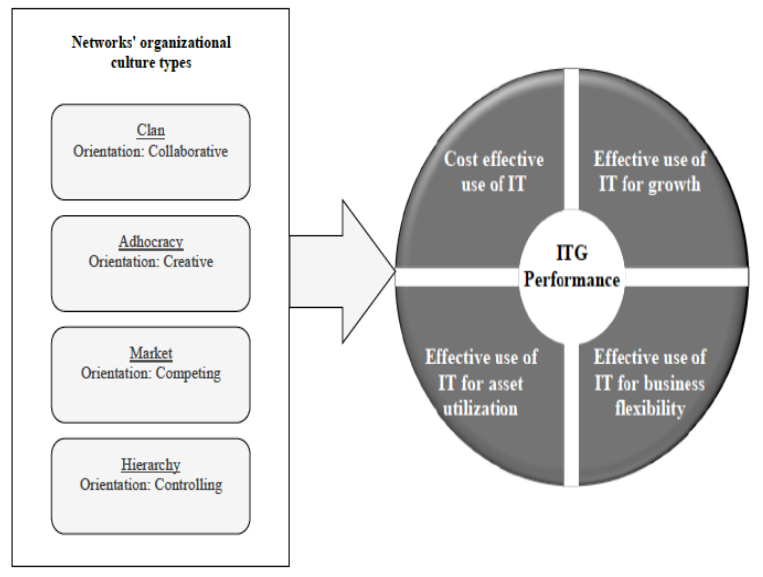

Figure 1. Research conceptual framework.

Networks have different types of organizational culture and this research is seeking to find the link between the networks' organizational culture and IT governance performance.

\section{Research methodology}

This research was conducted as a case study to explore dynamics of the studied phenomenon. Yin [39] recommends case study when investigating "how" or "why" research questions and when the phenomenon is new. The case study is a suitable method to respond to our research question, "How organizational cultures influence IT governance performance in different virtual networks in a large organization?" Our phenomenon, global virtual networks, as an organizational design is new and has not received extensive attention.

The case study was performed in Cemex, which is a large global building material company. Cemex has recently established global virtual networks for collaboration on a global level. In such case studies, a variety of data resources such as interviews, archival data, and observations may be used [40].

The main source of data for this case study was semi-structured interviews and white papers and presentations supplied by the company. Most of the interview questions were open- ended questions and focused on the leadership and culture of networks and the role of IT in facilitating virtual networks' performance. A total of 11 face-to-face interviews were conducted with the key leaders of the Cemex global virtual networks in autumn 2016. These networks represent different organizational culture orientations. All interviews were recorded and transcribed. After conducting 11 interviews, there was no more new information revealed and the data collection ended (See Table 1 in Appendix I).

In addition to the interviews, Cemex provided internal documents regarding the company's strategic plans, the global virtual networks' aims and structure, IT platform performance, different decision makers and organizational culture changes. To boost the validity and reliability of this research, triangulation was done between interviews, and Cemex internal documents [41].

A qualitative approach is used in this research, since a qualitative study is more likely to obtain unexpected information than the quantitative approach, which is more structured and detailed from the beginning [41]. First, all interviews were recorded, transcribed, coded, and then themes emerged from the interview data analysis of the interviews [42]. The categorization of the initial codes was mainly based on the concepts of virtual networks [32], IT governance performance $[11 ; 2]$ and organizational culture dimensions [35].

\section{Case description: Cemex background}

Cemex is a global leader in the ready-mix concrete industry and one of the largest building materials manufacturers in the world. Cemex has approximately 44,000 employees worldwide. They produce, distribute, and sell cement, readymix concrete, aggregates, and related building materials in more than 50 countries. In order to maintain its position as a leader in the market and compete with its competitors, Cemex strives to strengthen internal commitment and innovation. Cemex created global initiatives in 2009 and then in 2014 Cemex introduced a set of 11 functional global networks emerging from those global initiatives (Figure 2). 


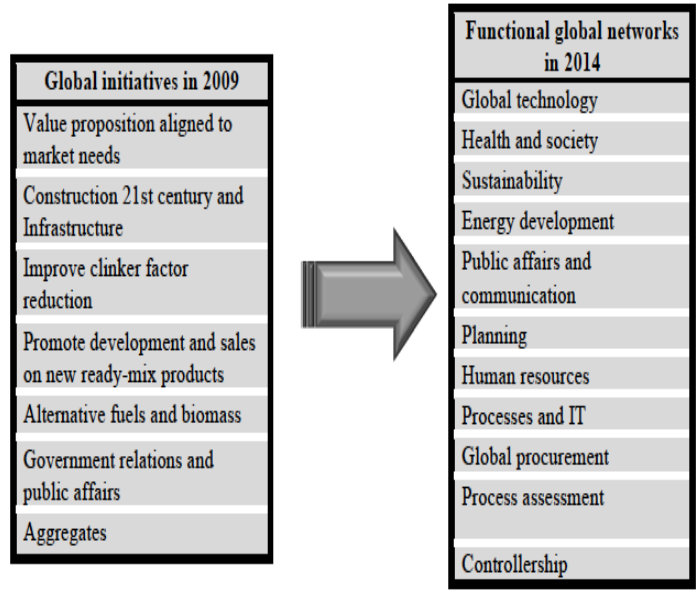

Figure 2. Cemex 11 functional global networks emerged from the global initiatives
The functional global networks cooperate as virtual teams and are endorsed by the Cemex executive committee (CEO). There may be some members of the global networks who are part of the executive committee too. Figure 3 represents the structure of the Cemex functional global networks and how they work.

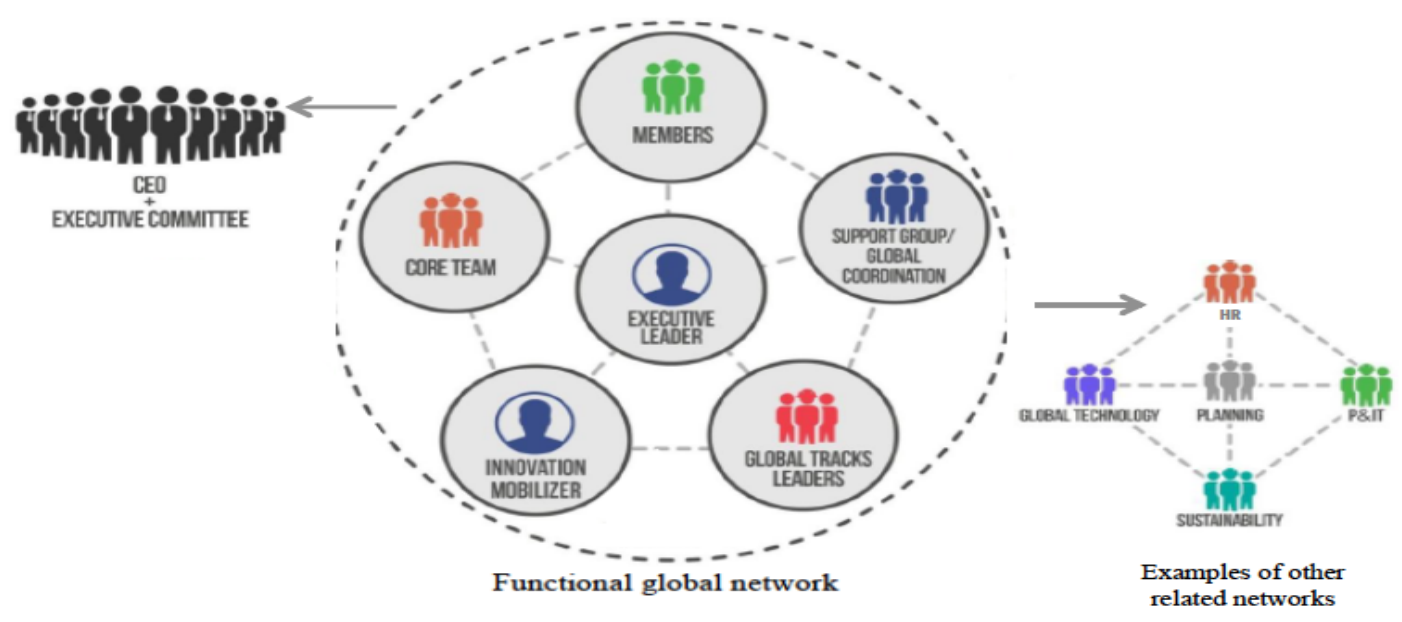

Figure 3. Functional global networks structure (adapted from Cemex technology office presentation)

Each one of the 11 functional global networks has its specific focus and leadership (see Figure 3). The networks may have diverse membership policies and the number of members in each network also varies. According to the Cemex managers, the organizational culture among these networks may also vary. For this research the key leaders of CEMEX functional global networks were interviewed. The following sections present the thematic analyses of the data on how the organizational culture in these networks influences IT governance performance outcomes.

\section{Analysis and discussion}

The findings from this case study provided evidence that each of the functional global networks at Cemex can be considered as a small organization collaborating to achieve the general organization strategic objectives.
According to the leader of Cemex global networks, the networks have different priorities and each of them has its own organizational culture. The themes included bellow describe how different IT governance priorities in Cemex's networks align with different organizational cultures. These themes are in line with the conceptual framework of this research. Quotes from interviewees 1-11 (Int. 1-11) are used to illustrate relevant themes. The organizational culture types were distinguished from the thematic analysis of the interviews using the OCAI model and the IT governance outcomes were distinguished through the four IT governance outcomes introduced by Weill and Ross (2004). The authors transcribed, coded and extracted themes according to the research conceptual framework. 


\subsection{Theme 1: Culture of collaboration desired for integration}

In 2014, when the functional global networks at Cemex emerged, there was an emphasis on the networks' integration by the Cemex CEO and the networks' leaders. The IT governance in each of these networks was different and it was very important for Cemex to extract the best practices. Most of the members of each network belong to a matrix organizational structure and that is why integration between these networks became so important. "All networks are leaded to the direction of having one single company and not different branches worldwide" (Int. 1). The "processes and IT" network leader states that "we use IT in our business process operations and in the recognition and evolution of different practices " (Int. 1). According to Cemex global managers, the first priority of the networks is to share the best IT governance practices, use the assets they have and respond to business needs at the lowest cost. Cemex IT governance outcomes are prioritized as follows: "1) IT value before the volume; 2) Asset management; 3) Aiming for efficiency; 4) Talent management" (Int. 1). However it is not an easy job to create integration among all these networks operating worldwide (Int. 2). Each of these networks has a specific leadership style and IT governance. For instance they may use different IT systems for similar projects. "Systems, Applications and Products in data processing (SAP) is used as our main transactional system; but it is not the only one system, we have five different systems worldwide and we are trying to reduce them to three" (Int. 1). This example illustrates very well the importance of the effective use of IT for asset utilization. Before these networks existed, there was no high integration between different Cemex worldwide units (Int. 3).

Cemex's global networks leaders expressed that when it comes to the integration of the networks, the most important IT governance outcomes are asset utilization and cost effective use of IT. Cemex leaders also believe that the culture of collaboration helps them most in promoting such integration (Int. 1, 5, 6). For example, "some local tax issues were solved by using the best practices revealed through collaboration with Cemex networks in another part of the world" (Int. 4). The leaders desired to increase teamwork, network members participation and free communication. These characteristics, desired by the networks' managers, align with the clan culture characteristics introduced by Cameron and Quinn [35]. To promote this culture, Cemex has recently adapted an IT platform (called SHIFT) through which all networks members can follow different projects, share ideas, report and compare results, and communicate best practices gained in projects in different parts of the world. However the uptake of this IT platform is still a challenge depending on networks' organizational cultures.

Figure 4 illustrates the characteristic explained by interviewees matching the characteristics of clan culture in relation to integration through IT governance asset utilization and cost saving. The IT platform used by the networks for collaboration is also connected to clan culture by a dashed arrow since it is a tool supporting the clan culture.

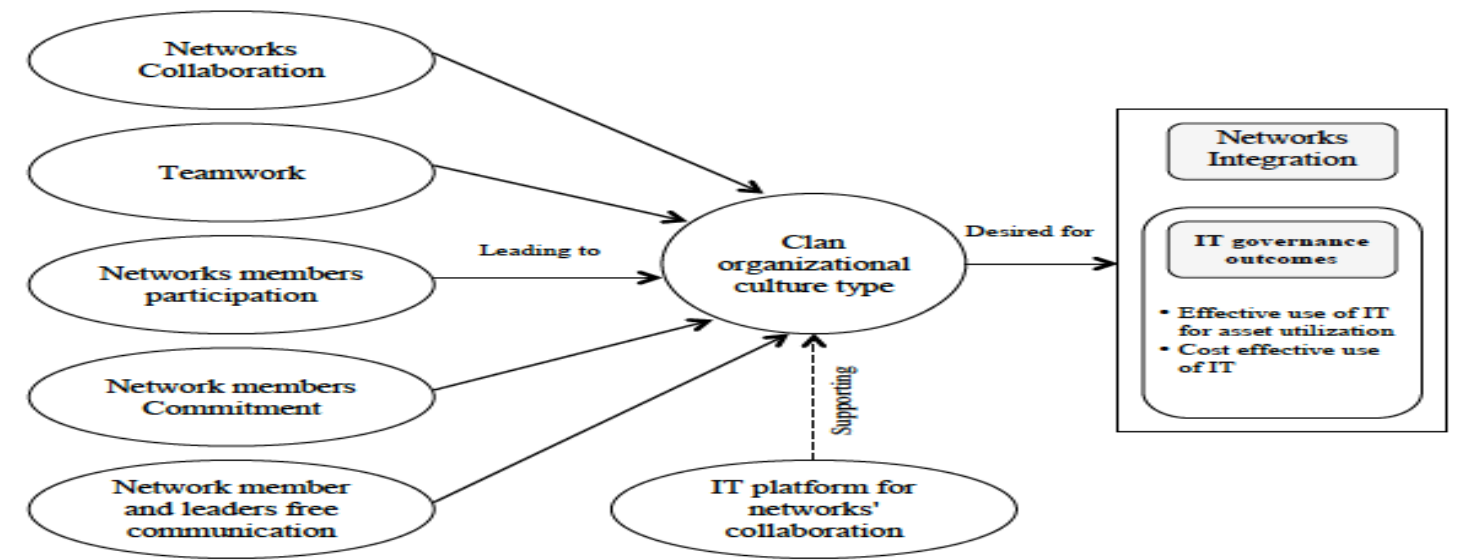

Figure 4. The organizational culture characteristics found to lead to clan culture desired for IT governance outcomes of effective use of IT for asset utilization and cost effective use of IT

As shown in Figure 4, the clan culture with the focus on collaboration improves integration. "The collaboration culture provides an environment for discussing new IT functions, finding the best practices and ways to cut costs. IT managers get informed about different processes and make better decision in process changes and evaluations" (Int. 4). 
5.2. Theme 2: Culture of innovation desired for business growth: center of excellence and network mobilizers are the key drivers

Innovation is a very important issue in Cemex networks leading them to come up with new solutions. Collecting new ideas from the networks and providing creative solutions have a high priority especially in the "Processes and IT" network. In January 2016, "Cemex Center of Excellence" was formed, which is linked with the "Processes and IT" network. "IT is not a provider to Cemex anymore, but is a part of Cemex business. The network used to be a client for IT but now IT (Processes and IT) belongs to the network" (Int. 2, 7). IT is now a driver for the whole business by playing two important roles: 1) IT needs to be cautious about its impact on every aspect of the processes, 2) IT needs to know how to react and make improvements in each aspect. This is where innovation becomes such significant issue. Now the top managers of Cemex assign strategic projects to the "Processes and IT" network. In order to accomplish such strategic projects, they need the expertise and ideas from all other networks too. When IT provides strategic solutions for business, then IT is effective in business growth [11]. Cemex network leaders and the innovation manager stress that when strategic solutions are requested from IT by the business, then an organizational culture with a focus on innovation and open communication is desired (Int. 1, 2, 4). This type of culture is specifically visible in the "Processes and IT" network which is now linked with the center of excellence too. The characteristics noted by the networks' leaders describing this desired culture match with the characteristics of the adhocracy organizational culture type introduced by Cameron and Quinn [35]. When seeking for strategic solutions from IT, the network leaders encourage an organizational culture in which "people can expose themselves easily, managers have dialogue with everyone and have a bidirectional approach" (Int. 1, 4, 6). The center of excellence is promoting this organizational culture. At the center of excellence "we are working to anticipate what the networks need and make solutions before they are needed" (Int. 2). "The scope of the networks range from very simple to very complex subjects. The networks members have four hours of meetings every month discussing how different global networks work, they try to find commonalities, innovative ideas and new solutions " (Int. 2).

Who is a network mobilizer?

To promote such an innovative culture, Cemex goes even one step further and uses expert innovation managers called "network mobilizers". A network mobilizer is a person usually with both IT and business administration background. "The mobilizers' general role is to push communication among the networks, generate questions for networks' leaders, find the topics that networks' members are afraid of exposing and bring these topics into discussions" (Int. 2). Cemex mobilizers were previously called "innovators", since their job is mostly focusing on improving innovation in the networks. The networks' members trust the mobilizer and transfer their ideas through the mobilizer. The mobilizers' activities supporting the adhocracy culture are: 1) Coordinating conversations among networks; 2) Expose questions and pursuit for answers; 3) Transfer different network managers' issues to the right people who may help, "mobilizers are the hub" (Int. 2).

4) Making notes from every conversation and referring to them in relevant situations.

5) Review the Key Progress Indicators (KPI) and align the IT solutions with them.

Furthermore, network mobilizers follow the KPI assessment results of leaders of different global networks and ask for their ideas. For instance a Dubai manager's ideas turned out to be beneficial in another project in Switzerland. Figure 5 signifies characteristics of adhocracy organizational culture explained by network leaders supporting the effective use of IT for business growth.

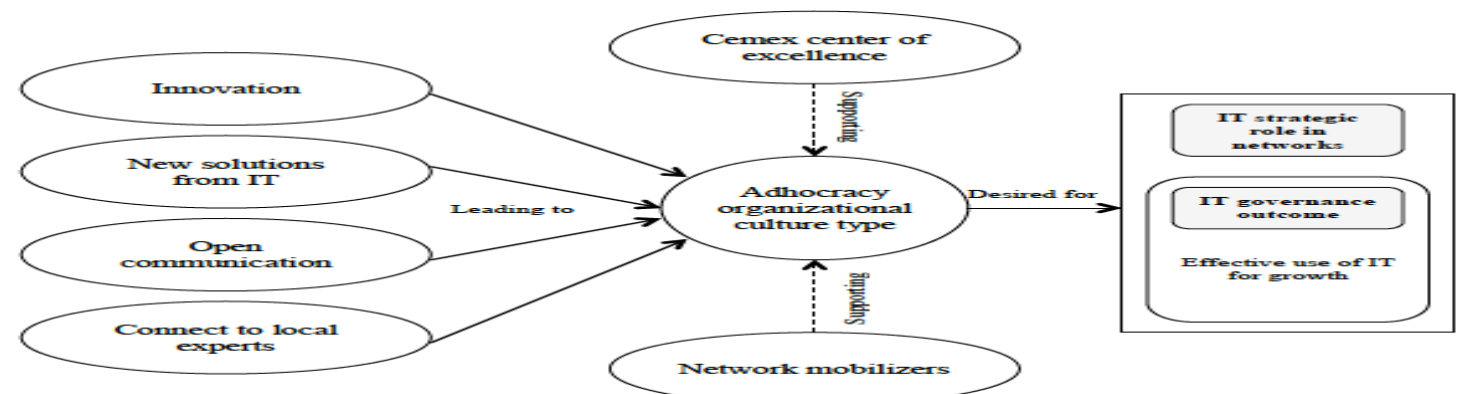

Figure 5. The organizational culture characteristics found to lead to an adhocracy culture desired for effective use of IT for business growth 
As shown in Figure 5, when there is a focus on the strategic role of IT, the desired characteristics explained by Cemex networks leaders match with the adhocracy culture. Cemex center of excellence and network mobilizers that is connected by dashed arrows to the adhocracy culture facilitate such an organizational culture.

As an example, the network mobilizer noted the pricing strategy issue. The center of excellence faced a request to create a structural model for product pricing. In this case the center of excellence analyzed all the business capabilities of Cemex around the world and "they were capable to do this job since they were part of it" (Int. 4). They used a strategic IT solution to create a model calculating the right price for products. This model was then applied for all Cemex transaction systems. This model covered all the aggregated operations and networks policies worldwide.

\subsection{Theme 3: Culture of competition and control desired for business flexibility and customer satisfaction}

This theme represents how different networks at Cemex are responsible for providing real time responses to customer needs and also cutting costs. IT governance needs to support the business in this case by providing business flexibility and cost saving. The organizational culture type found to be desired by the Cemex networks dealing with this issue is a mix of hierarchy and market culture.

There are four objectives communicated by the CEO: 1) Priority for health and safety, 2) One global Cemex, 3) Recovering the financial status, 4) Customer centricity.

Each of the functional global networks' needs to work through the above objectives and IT also needs to be aligned with these objectives. When it comes to health and safety, the networks' leaders state that there should be a considerable control of all IT processes involved in health and safety. Therefore the role of IT governance is very important in:

"1) Finding all Cemex processes that directly or indirectly involve health and safety issues and 2) make standardized policies to insure the quality of health and safety in those processes around the world" (Int. 1, 8). In some of the networks, there are more health and safety issues involved. According to those networks' leaders the desired organizational culture in those networks is more directed to monitoring and control. All the processes involved with health and safety are standardized and there are many policies for them. The standard KPIs are defined and communicated formally to all network members and controlled regularly. The vice-presidents of the networks report monthly to the networks' presidents and the networks' presidents report to the executive committee every two or three months. At the executive committee, the first topic that is reviewed is health and safety and they search for embedded problems. "IT governance has a significant role here by creating solutions to gain a lot of visibility in all processes and also provide tracking procedures" (Int. 7, 10). When all the steps of the processes involving health and safety are visible to all networks, it will be easier to control and monitor them. This also prevents extra costs that can occur because of unclear processes and an unstandardized monitoring system (Int. 6, 9).

As an organizational culture activity, Cemex provides many training programs and has different teams to review the outcomes. These organizational culture characteristics match with the characteristic of the hierarchy culture focusing on control.

The other issue mentioned by the Cemex CEO is customer centricity. "IT needs to be very agile to customer needs" (Int. 5, 11). Customers are both internal and external customers. The reason for agility in response to customer needs is that the competitors may fulfill them before Cemex. In this case the desired organizational culture characteristics explained by the leaders match with the "market" organizational culture type introduced by Cameron and Quinn [35]. In the market organizational culture the focus is on competition, profitability, and customers. The general leader of Cemex global networks states that "we are a leader in the ready-mix industry and we want to remain a leader" (Int. 5). When there is a change in the market or customer needs, it is crucial for Cemex as an industry leader to respond to that change as quickly as possible. "Real-time response to customer needs is possible only through the IT governance" (Int. 4). Figure 6 shows the hierarchy and market organizational culture characteristics found to be related to IT governance outcomes of business flexibility and cost effectiveness of IT. 


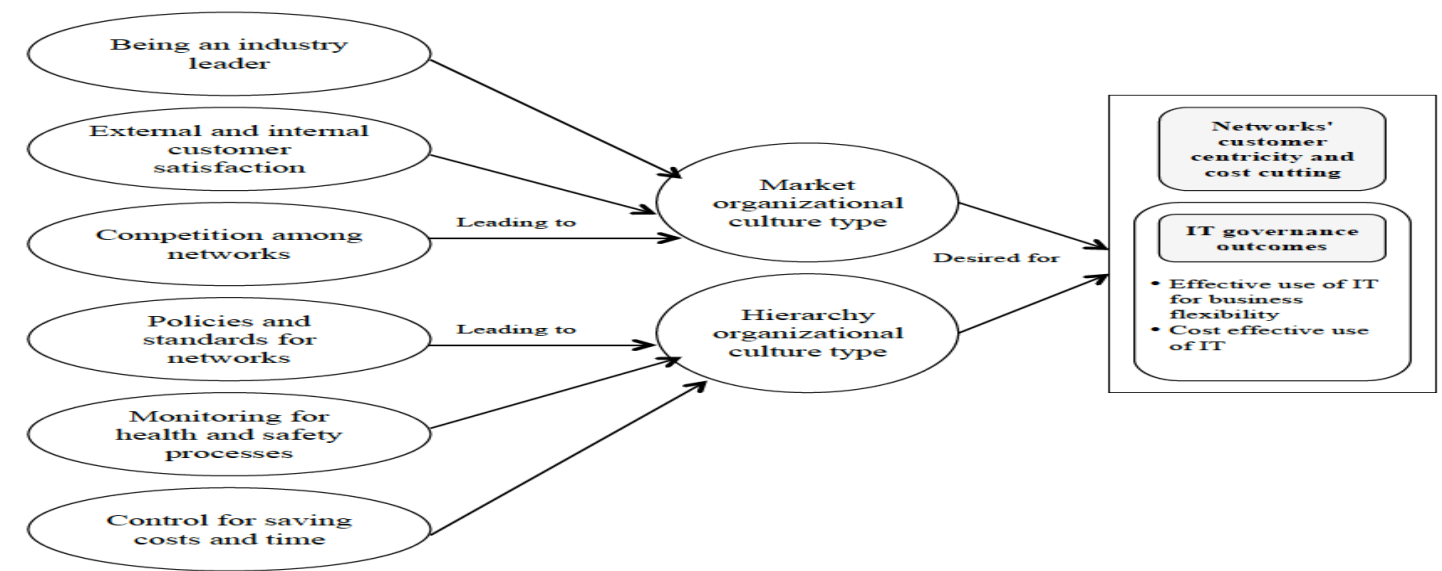

Figure 6. The organizational culture characteristics found to lead to a market and hierarchy culture desired for effective use of IT for business flexibility and cost cutting

As represented in Figure 6, when different networks at Cemex focus on customer satisfaction, competition with their competitors and cutting costs at the same time, they lean toward a hierarchy and market organizational culture. These organizational culture types are desirable in the networks for gaining effective use of IT for business flexibility and cost cuttings.

\subsection{Different organizational culture types desired for different IT governance performance outcomes}

Figure 7 summarizes the most important findings of this case study. It is not surprising that in such a complex organization with different networks, diverse organizational culture types exist. Based on the priority that each IT governance performance outcome has, a different type of organizational culture proves most appropriate. Figure 7 also shows examples of IT governance outcomes from Cemex networks. Cemex leaders related these examples to the desired organizational culture types.
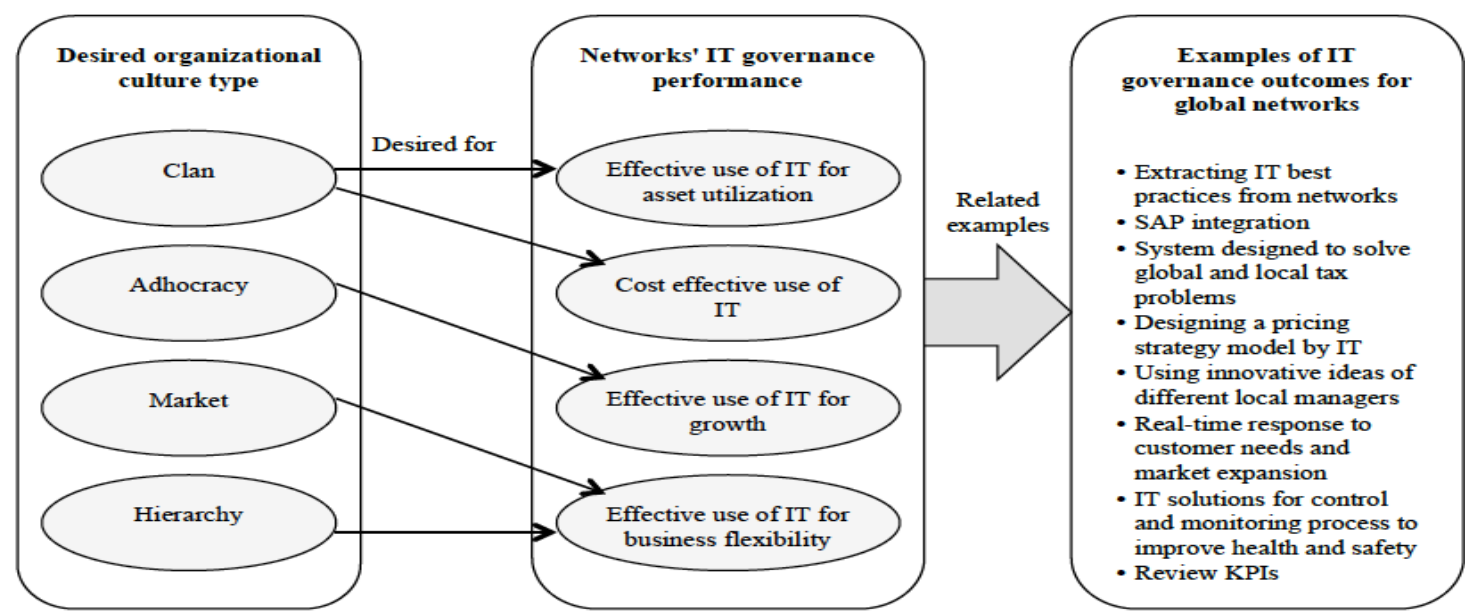

Figure 7. Summary of finding from case study: Different organizational culture types found to be desired for each IT governance performance outcome with related examples of outcomes

In Figure 7, each organizational culture type is linked to the relevant IT governance outcome mentioned by the networks leaders. According to Cameron and Quinn [35], the organizational culture can be a combination of all four types of clan, adhocracy, market and hierarchy. However there will be one type as the dominant one in each organization. The data from this case study also shows that a mixture of all four organizational types can exist in each network. However one or two organizational culture types are more dominant based on the network priorities and focus.

\section{Conclusions, limitations and future research}

This research provided an explanatory study to answer the research question of "how 
organizational culture influence IT governance performance different global virtual networks in a large organization". Managers have often blamed organizational culture when IT governance projects fail; however this interdisciplinary topic has gained little attention in previous academic research. This topic was approached in this research by performing a case study in a large organization with complex functional global networks. The networks in this organization are lead in diverse ways, have different priorities, and align with different organizational culture types. The data were collected through 11 interviews with the network leaders, and archival documents from the organization provided sources of data triangulation. The data were analyzed thematically according to the conceptual framework of the research.

The main conclusion of this research is that organizational culture does influence the performance outcomes of IT governance. The case study indicated that the networks need different organizational culture types based on the priorities they have for IT governance outcomes. The first theme revealed that the network leaders prefer clan organizational culture characteristics such as teamwork, collaboration and member commitments, when they prioritize the effective use of IT for asset utilization and cost effective use of IT. The networks even use an IT platform particularly designed for network collaboration and promoting the clan culture. Through the second theme, it was found that the network leaders prefer to adopt a culture of adhocracy with a focus on innovation, open communication, and finding new solutions, when they prioritize the strategic role of IT. Specifically, the leaders of the processes and IT network that prioritizes the effective use of IT for business growth highlighted this type of organizational culture. The center of excellence and the network mobilizers are the supporting assets of the adhocracy culture. The last theme revealed that when the networks focus on the effective use of IT for business flexibility, they prefer to foster a combination of market and hierarchy organizational culture type. The market culture focuses on customer satisfaction and quick responses to business needs, while the hierarchy organizational culture focuses on control and monitoring of the outcomes.

All in all, the findings of this research contribute to the academic research in the field of IT governance by investigating how the organizational culture of global virtual networks influences IT governance performance. This domain had not been thoroughly explored through an empirical study before. While there may be a combination of organizational culture characteristics existing in an organization, different networks may foster one type of culture based on their priorities and that influences the outcomes of their IT governance.

As with any other research, this research has some limitations. First, this case study was conducted in one organization. This organization included several virtual working networks with different types of organizational cultures making this case complicated. The other limitation is that Cemex has recently established the global virtual networks and these are still changing. Moreover, the findings are based on the opinions of the network leaders and not based on all of the network members.

Directions for future research could be more detailed studies on the organizational culture of global virtual networks and how it should be shaped in these networks. Furthermore, the findings of this study can be used for future research on suggestions for organizational culture changes in order to improve IT governance performance in organizations.

\section{References}

[1] E. S. Couto, M. F. C. Lopes, and R. D. Sousa, "Can IS/IT Governance Contribute for Business Agility?", Procedia Computer Science, 64, 2015, pp. 1099-1106.

[2] S. De Haes and W. Van Grembergen, Enterprise Governance of IT: Achieving Alignment and Value (Second edition), Springer, 2015.

[3] A. Sesay, and R. Ramirez, "Theorizing the IT Governance Role in IT Sourcing Research", AMCIS 2016 Proceedings, 2016.

[4] R. Peterson, "Crafting Information Technology Governance", Information Systems Management, (21) 4, 2004, pp.7-23.

[5] P.L. Bowen, M. Y. Cheung and F. H. Rohde, "Enhancing IT Governance Practices: A Model and Case Study of an Organization's Efforts", International Journal of Accounting Information Systems, 8(3), 2007, pp. 191-221.

[6] L. A. Kappelman, E. Mclean, V. Johnson and N. Gerhart, "The 2014 SIM IT Key Issues and Trends Study", MIS Quarterly Executive, 13(4), 2014, pp. 237-263.

[7] E. N. Nfuka and L. Rusu, "Critical Success Framework for Implementing Effective IT Governance in Tanzanian Public Sector Organizations", Journal of Global Information Technology Management, 16(3), 2013, pp. 53-77.

[8] ISACA, "Top Business/Technology Issues Survey Results 2011", Retrieved on January 5, 2017, from http://www.isaca.org/KnowledgeCenter/Research/Research 
Deliverables/Pages/Top-Business-

Technology Issues-Survey-Results-2011.aspx.

[9] F. Bergeron, A. M. Croteau, S. Uwizeyemungu and L. Raymond, "A Framework for Research on Information Technology Governance in SMEs", Strategic IT Governance and Alignment in Business Settings, 2017, p. 53.

[10] M. Alvesson, Understanding Organizational Culture, Sage Publications Ltd, London, 2012.

[11] P. Weill, J. W. Ross, IT Governance: How Top Performers Manage IT Decision Rights for Superior Results, Harvard Business School Press, Watertown, MA, 2004.

[12] E.W. Bernroider, "IT Governance for Enterprise Resource Planning Supported by DeLone-McLean Model of Information Systems Success", Information and Management, 45(5), 2008, pp. 257-269.

[13] W. Van Grembergen and S. De Haes, "Measuring and Improving IT Governance Through the Balanced Scorecard", Information Systems Control Journal, 2(1), 2005, pp. 35-42.

[14] S. De Haes, W. Van Grembergen, "An Exploratory Study into IT Governance Implementations and its Impact on business/IT Alignment", Information Systems Management, 26 (2), 2009, pp. 123-137.

[15] B. Bell and S. Kozlowski, "A Typology of Virtual Teams", Group \& Organization Management,27, 2002, pp.14-49.

[16] P. Kanawattanachai and Y. Yoo, "The Impact of Knowledge Coordination on Virtual Team Performance over Time", MIS Quarterly, 31(4), 2007, pp. 783-808.

[17] A. Powell, G. Piccoli and B. Ives, "Virtual Teams: a Review of Current Literature and Directions for Future Research", ACM Sigmis Database, 35 (1), 2004, pp. 6-36.

[18] L. L. Martins, L.L., Gilson, and M. T. Maynard, "Virtual Teams: What Do We Know and Where Do We Go from Here?", Journal of Management, 30(6), 2004, pp.805-835.

[19] C. B. Gibson and S. G. Cohen, Virtual Teams That Work: Creating Conditions for Virtual Team Effectiveness, Jossey-Bass, San Francisco, 2003.

[20] J. Heckler and A. Powell, "IT and Organizational Agility: A Review of Major Findings", MWAIS, 2016.

[21] G.R. Jones, Organizational Theory, Design, and Change 5th ed., Pearson Prentice Hall, NJ, 2007.

[22] P. Aasi, L. Rusu and S. Han, "Culture Influence on IT Governance: What We Have Learned", International Journal of IT/Business Alignment and Governance, 5(1), 2014, pp. 34-49.

[23] L. A. Janssen, E. M. Luciano, and M. G. Testa, "The Influence of Organizational Culture on IT Governance: Perception of a Group of IT Managers from Latin American Companies", HICSS 2013 Proceedings, 2013.

[24] W. Ke, and K. K. Wei, "Factors Affecting Trading Partners' Knowledge Sharing: Using the Lens of Transaction Cost Economics and SocioPolitical Theories", Electronic Commerce Research and Applications, 6(3), 2007, pp. 297-308.

[25] A. E. Brown and G. G. Grant," Framing the Frameworks: A Review of IT Governance
Research", Communications of the Association for Information Systems, 15, 2005, pp. 696-712.

[26] D. E. Leidner and T. Kayworth, "Review: A Review of Culture in Information Systems Research: Toward a Theory of Information Technology Culture Conflict", MIS Quarterly, 30(2), 2006, pp.357-399.

[27] S. De Haes, W. Van Grembergen, and R. S. Debreceny, "COBIT 5 and Enterprise Governance of Information Technology: Building Blocks and Research Opportunities", Journal of Information Systems, 27(1), 2013, 307-324.

[28] K. Jairak, P. Praneetpolgrang and P. Subsermsri, "Information Technology Governance Practices Based on Sufficiency Economy Philosophy in the Thai University Sector", Information Technology and People, 28 (1), 2015, pp. 195-223.

[29] S. Dittes, and S. Smolnik, "Is It an Antecedent? Is It an Outcome? No, It's Culture! Understanding the Relationship between Cultural Values and the Use of Information Systems Fostering Collaboration", HICSS 2016 Proceedings, 2016.

[30] T. Huygh, S. De Haes, A. Joshi, W. Van Grembergen, and D. Gui, "Exploring the Influence of Belgian and South-African Corporate Governance Codes on IT Governance Transparency", HICSS 2017 Proceedings, 2017.

[31] IT Governance Institute ITGI, "Board Briefing on IT Governance, 2nd edition, 2003.

[32] G. Hertel, S. Geister and U. Konradt, "Managing Virtual Teams: A Review of Current Empirical Research", Human Resource Management Review, 15(1), 2005, pp.69-95.

[33] E. H. Schein, The Corporate Culture Survival Guide (eds.), Jossey-Bass, CA, 2010.

[34] T. Dahlberg and H. Kivijarvi, "An Integrated Framework for IT Governance and the Development and Validation of an Assessment Instrument", HICSS 2006 Proceedings, 2006.

[35] K. S. Cameron and R. E. Quinn, Diagnosing and Changing Organizational Culture: Based on the Competing Values Framework, John Wiley \& Sons, CA, 2011.

[36] G. Hofstede, Culture's Consequences: Comparing Values, Behaviors, Institutions, and Organizations Across Nations, 2nd edition, Sage, Thousand Oaks, CA., 2001.

[37] OCAI Online. (2010). OCAI Pro Example Report: Dutch Public Administration. Retrieved January 16, 2017 from https://www.ocaionline.com/userfiles/file/ocai_pro_example

[38] J. Suderman, "Using the Organizational Cultural Assessment (OCAI) as a Tool for New Team Development", Journal of Practical Consulting, 4(1), 2012, pp. 52-58.

[39] R. K. Yin, Case Study Research: Design and Methods.5th Edition, Sage, CA, 2013.

[40] K. M. Eisenhardt and M. E. Graebner, "Theory Building from Cases: Opportunities and Challenges", Academy of Management Journal, 50(1), 2007, pp. 25-32.

[41] M. Myers, Qualitative Research in Business and Management, SAGE, London, 2009.

[42] V. Braun and V. Clarke, "Using Thematic Analysis in Psychology", Qualitative Research in Psychology, 3(2), 2006, pp. 77-101. 


\section{Appendix I}

Table 1 provides more information regarding the interviews.

Table 1. Interviews information

\begin{tabular}{|c|c|c|c|c|}
\hline $\begin{array}{l}\text { Interview } \\
\text { number }\end{array}$ & Interviewrees' positions & Related network & $\begin{array}{c}\text { Years } \\
\text { at } \\
\text { Cemex }\end{array}$ & $\begin{array}{l}\text { Interview } \\
\text { length in } \\
\text { minutes }\end{array}$ \\
\hline 1 & \begin{tabular}{|l|} 
Director of processes \& \\
IT/ Center of excellence
\end{tabular} & All networks & 14 & 70 \\
\hline 2 & $\begin{array}{l}\text { Cemex functional } \\
\text { networks mobilizer }\end{array}$ & All networks & 11 & 60 \\
\hline 3 & \begin{tabular}{|l} 
Research group \\
innovation manager
\end{tabular} & All networks & 11 & 60 \\
\hline 4 & \begin{tabular}{|l|} 
Leader of Cemex \\
functional networks/ \\
Center of excellence \\
\end{tabular} & All networks & 11 & 60 \\
\hline 5 & IT manager & Processes \& IT & 19 & 60 \\
\hline 6 & $\begin{array}{l}\text { Head of global processes } \\
\text { in center of excellence }\end{array}$ & Processes \& IT & 18 & 50 \\
\hline 7 & \begin{tabular}{|l|} 
Process center of \\
excellence manager
\end{tabular} & $\begin{array}{l}\text { Planning/Processes } \\
\text { \& IT }\end{array}$ & 9 & 60 \\
\hline 8 & $\begin{array}{l}\text { Head of business } \\
\text { process consulting }\end{array}$ & Global procurement & 11 & 60 \\
\hline 9 & $\begin{array}{l}\text { Global processes } \\
\text { manager/ Processes \& } \\
\text { IT }\end{array}$ & \begin{tabular}{|l|} 
Global procurement \\
Processes \& IT
\end{tabular} & 6 & 60 \\
\hline 10 & $\begin{array}{l}\text { Head of business } \\
\text { process methodologies }\end{array}$ & $\begin{array}{l}\text { Controllership/ } \\
\text { Process assessment }\end{array}$ & 7 & 50 \\
\hline 11 & $\begin{array}{l}\text { IT planning senior } \\
\text { consultant }\end{array}$ & $\begin{array}{l}\text { Global technology } \\
\text { Processes \& IT }\end{array}$ & 15 & 60 \\
\hline
\end{tabular}

